\title{
EXCLUSÃO JUDICIAL DE SÓCIOS E DISSOLUÇÃO PARCIAL NAS SOCIEDADES ANÔNIMAS
}

\section{RESUMO}

Lucas Salles Moreira Rocha ${ }^{1}$ Tereza Cristina Monteiro Mafra ${ }^{2}$

A exclusão de sócios nas sociedades anônimas, ressalvado o sócio remisso, gera controvérsias, tendo em vista a ausência de tratamento da matéria na Lei 6.404/76. Contribuindo para o alargamento da discussão, o Novo Código de Processo Civil introduziu regramento subjetivo acerca da dissolução parcial das sociedades anônimas. Assim, o presente estudo buscará analisar a possibilidade de se excluir sócio de sociedade anônima, via ação de dissolução parcial, bem como sugerir algumas hipóteses em que tal medida poderia ser tomada. Os estudos serão realizados pelo método descritivo, a partir da análise de medidas jurídicas que podem ser tomadas para estruturação patrimonial.

PALAVRAS-CHAVE: Sociedade Anônima; Exclusão; Sócio; Dissolução Parcial.

\section{JUDICIAL EXCLUSION OF MEMBERS AND PARTIAL DISSOLUTION OF CORPORATIONS}

\begin{abstract}
The exclusion of members in corporations, except for the remiss shareholder, generates controversy due to the absence of treatment of the matter in Law 6.404/76. Contributing to the extension of the discussion, the New Code of Civil Procedure introduced a subjective rule on the partial dissolution of corporations. Thus, the present study will analyze the legal possibility of excluding members from a corporation, via partial dissolution action, as well as suggest some hypotheses in which such a measure could be taken. The studies will be carried out using the exploratory method, through analysis of jurisprudence, doctrine and applicable legislation.
\end{abstract}

KEYWORDS: Corporation; Exclusion; Member; Partial Dissolution.

\section{INTRODUÇÃO}

A possibilidade de exclusão de sócios no âmbito das sociedades anônimas é tema que gera intensos debates entre os profissionais da área do direito, tendo em vista a ausência de tratamento específico da matéria na Lei 6.404/76. Contribuindo para o alargamento das

\footnotetext{
1 Mestrando em Direito pela Faculdade de Direito Milton Campos (FDMC), pós-graduado em Direito Corporativo pelo Instituto Brasileiro de Mercado de Capitais (IBMEC-MG), graduado em Direito pela Faculdade de Direito Milton Campos (FDMC). E-mail: rocha.lucas@ gmail.com.

2 Mestre e Doutora em Direito Civil pela Universidade Federal de Minas Gerais - UFMG, Minas Gerais, MG, (Brasil). Professora da Faculdade de Direito Milton Campos, Minas Gerais, MG, (Brasil). E-mail: tereza.c.mafra@terra.com.br.
} 
discussões, o Novo Código de Processo Civil, em vigor desde 18 de março de 2016, trouxe disposições expressas acerca da dissolução parcial de sociedades.

Dentre as disposições processuais inseridas no ordenamento pátrio, destaca-se a que define que a ação de dissolução parcial de sociedade pode ter por objeto a resolução da sociedade, contratual ou simples, em relação ao sócio, em decorrência de exclusão (art. 599, I). Concomitantemente, um dos parágrafos no citado dispositivo consignou, expressamente, que as sociedades anônimas podem ser objeto de dissolução parcial, desde que reste demonstrado que esta não pode preencher o seu fim $\left(\operatorname{art} .599, \S 2^{\circ}\right)$.

Nota-se que os dispositivos citados foram restritivos quanto à possibilidade de dissolução parcial das sociedades anônimas, não abarcando, à primeira vista, a possibilidade de resolução da sociedade em face de um dos acionistas, em decorrência de exclusão.

Tendo em vista o papel fundamental que as sociedades empresárias ocupam na sociedade, o instituto da exclusão de sócios, usualmente invocado para mitigar riscos ao exercício regular da atividade social, mostra-se um instrumento de grande importância, que apresenta, entretanto, grave insegurança jurídica no âmbito das sociedades anônimas.

Diante do problema posto, o presente artigo irá, pelo método exploratório, analisar os institutos jurídicos que permeiam a matéria, a partir de entendimentos doutrinários, jurisprudenciais, e da legislação aplicável. Com base na pesquisa realizada, buscar-se-á, sem esgotar o tema, demonstrar a possibilidade de ajuizamento de ação de dissolução parcial das sociedades anônimas, em determinados casos, para exclusão de acionistas.

Para tanto, o presente estudo irá, inicialmente, esclarecer brevemente a distinção entre sociedades contratuais e sociedades institucionais. Posteriormente, far-se-á uma análise acerca do enquadramento das sociedades anônimas, buscando demonstrar a possibilidade de estas se encaixarem não apenas no perfil de uma sociedade institucional, mas também de uma sociedade contratual, em determinadas hipóteses.

Realizada a contextualização acima, serão tecidos comentários acerca da dissolução parcial de sociedades, passando por sua origem, no princípio da preservação da empresa, até chegar à sua aplicação e previsão expressa no Novo Código de Processo Civil.

Será analisada, por fim, a possibilidade de exclusão de sócios em decorrência da impossibilidade de preenchimento da finalidade social e a partir de aplicação subsidiária das disposições previstas no Código Civil, para, em seguida, buscar demonstrar a possibilidade de 
aplicação do art. 599, I, do Código de Processo Civil em vigor, inicialmente limitado às sociedades simples e contratuais, a determinadas sociedades anônimas.

\section{TIPOLOGIA DAS SOCIEDADES CONTRATUAIS E INSTITUCIONAIS}

\subsection{Sociedades contratuais e sociedades institucionais}

As sociedades ingressam no mundo jurídico a partir dos seus atos constitutivos, que se formam em decorrência de manifestação de vontade dos sócios. Esta declaração de vontade dos sócios pode se revestir de diferentes naturezas jurídicas, a depender da forma como é formalizada. Tradicionalmente, as sociedades podem ser classificadas a partir dos atos constitutivos como: (i) sociedades contratuais; ou (ii) sociedades institucionais.

Tullio Ascarelli, jurista italiano que viveu alguns anos no Brasil, desenvolveu a teoria do contrato plurilateral. De acordo com o estudo desenvolvido pelo citado doutrinador, chegou-se à conclusão de que o ato constitutivo das sociedades não poderia se tratar de um contrato bilateral, em que são atribuídos às partes direitos e deveres opostos, mas de um contrato plurilateral, em que os direitos e deveres dos sócios são independentes e destinados ao alcance de uma finalidade comum.

A teoria de Ascarelli foi aceita de forma quase unânime pela doutrina pátria, sendo possível afirmar que a teoria do contrato plurilateral se aplica às sociedades regidas pelo Código Civil, conforme bem exposto por Marlon Tomazette (2013, p. 218):

O regime contratual geral, acrescido das peculiaridades do contrato plurilateral, as quais são aptas e superar os inúmeros problemas decorrentes das relações societárias, mostra, a nosso ver, uma solução coerente e tecnicamente correta a respeito da natureza jurídica do ato constitutivo das sociedades. Diante disso, tal doutrina possui a aceitação quase unânime da doutrina pátria, podendo-se afirmar que, em relação às sociedades regidas pelo Código Civil de 2002, a natureza jurídica do seu ato constitutivo é de um contrato plurilateral.

A teoria da instituição, por seu turno, foi originalmente desenvolvida pelo jurista francês Maurice Hauriou (1968, p. 49), para quem instituição é uma ideia de obra ou de empresa que se realiza e perdura juridicamente em um meio social e, para a realização desta ideia, organiza-se um poder que dele extrai os órgãos necessários, e, de outro lado, entre os membros do grupo social interessado na realização dessa ideia, produzem-se manifestações de comunhão dirigidas por órgãos do poder e regulamentadas por procedimentos. 
O cerne da instituição, portanto, reside na realização da ideia posta, sendo a vontade dos sócios, contrariamente ao que ocorre nos contratos, sobreposta pela finalidade a ser alcançada. A respeito do tema, leciona Marlon Tomazette (2013, p. 218):

Vê-se, pois, que a ideia fundamental na instituição é a obra a realizar, possuindo somenos importância a vontade dos sócios. Em tal ato, a vontade dos sócios é restrita à aceitação da disciplina, sem uma preocupação maior quanto aos efeitos, ao contrário do que ocorreria nos contratos. A vontade dos sócios não seria tão determinante na vida da sociedade, quanto à função a ser exercida. Adotando a teoria da instituição, há uma subordinação dos direitos e interesses privados aos fins que se quer realizar.

A teoria da instituição, entretanto, sofreu algumas críticas, como a realizada pelo jurista italiano Antonio Cicu (1947, p. 49):

O erro da mesma está, para nós, nisto: em que restringe excessiva e injustificadamente a concepção de contrato. Se já se deve considerar como estranho a esta ideia o fato de que uma minoria deva submeter-se a um acordo de maioria, nós não vemos porque o conceito de instituição não deva encontrar-se também na sociedade civil e na copropriedade. $\mathrm{O}$ que no fundo há de verdade na teoria, está no conceito, que ela não expressa exatamente, de um estado de sujeição da pessoa que se produz independentemente de sua vontade e responsabilidade; mas precisamente isto não pode derivar do só fato de que em uma relação jurídica se entre em virtude de uma simples adesão.

Em síntese, para Cicu (1947, p. 49), o principal equívoco de Hariou está em restringir a noção de contrato aos casos em que o consentimento das partes regula a atividade dos contratantes com base na previsão atual de seus atos e confina, em contrapartida, na tese institucional, todos os casos em que o consentimento se apresenta como mera aceitação, sem preocupação atual com as atividades da instituição.

\subsection{Enquadramento das sociedades anônimas}

Conforme se infere de trecho extraído da "Exposição de Motivos" da Lei 6.404/76, citada por Rubens Requião (2010, p. 37), a reforma legislativa concernente às sociedades anônimas fundou-se na teoria da instituição:

Entre a sociedade anônima de há trinta anos atrás, concebida basicamente como empresa familiar numa economia estagnada, e a moderna corporação em constante apelo ao crédito público, a diferença não é apenas quantitativa, de aumento de tamanho: é qualitativa. Há muito a S.A. deixou de ser um contrato de efeitos limitados para seus poucos participantes: é uma instituição que concerne a toda a economia do País, ao crédito público, cujo funcionamento tem que estar sob o controle fiscalizador e o comando econômico das autoridades governamentais. A síntese é da exposição de 
motivos do projeto italiano: 'a disciplina das sociedades por ações e sua modificação constituem, sobretudo, um elemento de política econômica e mais genericamente um fato político'.

Parte da doutrina reforça, ainda, o acolhimento da teoria da instituição pela Lei 6.404/76, tendo em vista a previsão do seu art. 116, parágrafo único, que determina que o poder de controle da sociedade anônima deve ser utilizado com a finalidade de cumprir seu objeto e função social, devendo o controlador respeitar seus deveres e responsabilidades perante os demais acionistas e a comunidade.

Tal entendimento persiste com base na importância e na finalidade social atribuída às grandes empresas capitalistas, que contribuem para a saúde econômica do país por meio de geração de empregos, recolhimento de tributos, geração de riquezas, dentre outros. Nesse sentido, embora haja nas sociedades anônimas um estatuto que estabeleça regras de convivência entre os sócios, prevalecem os interesses públicos sobre os privados, especialmente nas sociedades de grande porte, conforme leciona Arnaldo Rizzardo (2007, p. 277):

O contrato social, denominado estatuto, atribui um caráter vinculativo dos sócios às cláusulas pactuadas, que faz predominar o princípio da vontade coletiva [...] No entanto, dada a importância pública das sociedades em especial de grande porte, e daquelas ligadas a importantes setores da economia nacional, adquiriu relevância a feição institucional que se dá às sociedades anônimas, sobrepondo-se às regras puramente contratuais, e predominando os interesses e propósitos públicos, com a decorrente ingerência do Estado na própria vida da sociedade.

Entretanto, muito se discute acerca da possibilidade de atribuição de caráter contratual a determinadas sociedades anônimas, pois, no Brasil, há inúmeras sociedades que adotam referido tipo societário, mas que são fechadas, de cunho familiar, não possuem circulação alguma de ações, não fazem captações no mercado financeiro e, ainda, têm a confiança e a pessoalidade como elemento preponderante da manutenção da união existente.

Rubens Requião (2010, p. 37) tece críticas ao projeto de reforma legal que culminou na Lei 6.404/76, tanto por não ter reconhecido que a instituição é formada pelo contrato plurilateral, quanto por ter relegado em segundo plano as pequenas e médias empresas, constituídas na forma de sociedades anônimas, mas fechadas e personalistas:

O mal, entretanto, do projeto de reforma, que se refletiu no sistema da lei hoje em vigor, foi precisamente o de não ter percebido que, quando se pode admitir que a sociedade anônima configure, após sua formação, uma instituição, não deixa de ser formada pelo contrato, e este de espécie plurilateral. Como instituição está ela voltada para a consecução do 'bem comum', visando primacialmente aos altos interesses coletivos, 
desvanecendo um tanto o interesse privado, perseguido pelos acionistas. Como contrato regula os interesses pessoais de seus membros.

O propósito, confessadamente repetido pelos autores do projeto de reforma, como das próprias autoridades governamentais, foi o de criar a estrutura da grande empresa brasileira. Acusa-se, por isso, o sistema da lei atual de ter relegado a segundo plano a pequena e média empresas constituídas como sociedade anônima, fechada e personalista, e que representem a massa de sociedades mercantis hoje existentes no Brasil.

Ainda, a complexa realidade das relações negociais dos dias atuais vem gerando entendimentos no sentido de que as sociedades anônimas podem, em determinados casos, ter características de sociedades contratuais:

A ideia, apreciada por estudiosos clássicos, de que o perfil do acionista não é levado em consideração por investidores interessados em ingressar na sociedade, opostamente ao que se verifica no âmbito das sociedades contratuais, especialmente as limitadas, também merece, a nosso ver, substancial reavaliação, em face da realidade societária de nosso ordenamento. Hodiernamente, com a crescente concentração de empresários e fenômenos ligados à tendência globalizante da economia, a avaliação do perfil e capacidade econômico-financeira de seus acionistas, especialmente do controlador é preocupação imediata daquele que adquire ações de companhia. (PIMENTA, 2004, p. 133).

Além de contratuais ou institucionais, as sociedades podem ser classificadas como sociedades de pessoas (em que prevalece o intuitu personae) ou de capital (em que prevalece o intuitu pecuniae), conforme explica Fábio Ulhoa Coelho (2012, p. 43):

As sociedades de pessoas são aquelas em que a realização do objeto social depende mais dos atributos individuais dos sócios que da contribuição material que eles dão. As de capital são as sociedades em que essa contribuição material é mais importante que as características subjetivas dos sócios.

O supracitado doutrinador defende (COELHO, 2012, p. 43), em seguida, que as sociedades limitadas podem ser de pessoas ou de capital, mas que as sociedades anônimas são sempre de capital:

A sociedade limitada pode ser de pessoas ou de capital, de acordo com o previsto no contrato social [...]. Por fim, as sociedades anônimas e em comandita por ações são sempre de capital.

A matéria, entretanto, não é pacífica na doutrina. Fran Martins (2011, P. 866), por exemplo, defende que o intuitu personae pode estar presente nas sociedades tipicamente capitalistas, em determinados casos:

Admite-se doutrinariamente a presença do elemento intuitu personae nas sociedades de forma jurídica capitalista típica, como é o caso das anônimas. Tal situação pode ser percebida através da existência de cláusulas restritivas à livre circulação das ações, elaboradas com fundamento no art. 36 da Lei 
6.404/76. Efetivamente, cláusulas estatutárias dessa natureza imprimem caráter familiar ou fechado à sociedade, e onde as qualidades pessoais dos sócios podem adquirir relevância no desenvolvimento das atividades sociais.

Seguindo este entendimento, o Superior Tribunal de Justiça reconheceu a possibilidade de haver, muitas vezes, "uma sociedade limitada travestida de sociedade anônima", conforme se infere do trecho abaixo, extraído da ementa dos Embargos de Divergência em Recurso Especial n. 111.294/PR, publicado em 10 de setembro de 2007, de relatoria do Ministro Castro Filho (BRASIL, 2007):

É inquestionável que as sociedades anônimas são sociedades de capital (intuito pecuniae), próprio às grandes empresas, em que a pessoa dos sócios não tem papel preponderante. Contudo, a realidade da economia brasileira revela a existência, em sua grande maioria, de sociedades anônimas de médio e pequeno porte, em regra, de capital fechado, que concentram na pessoa de seus sócios um de seus elementos preponderantes, como sói acontecer com as sociedades ditas familiares, cujas ações circulam entre os seus membros, e que são, por isso, constituídas intuito personae. Nelas, o fator dominante em sua formação é a afinidade e identificação pessoal entre os acionistas, marcadas pela confiança mútua. Em tais circunstâncias, muitas vezes, o que se tem, na prática, é uma sociedade limitada travestida de sociedade anônima, sendo, por conseguinte, equivocado querer generalizar as sociedades anônimas em um único grupo, com características rígidas e bem definidas.

Diante da breve exposição realizada acima, constata-se que há controvérsias quanto à possibilidade de a sociedade anônima poder, ou não, se enquadrar como sociedade contratual ou de pessoas. Não obstante tal fato, o presente estudo filia-se ao entendimento de que existe tal possibilidade, desde que se trate de sociedade fechada, que não realize captações no mercado financeiro e, ainda, que tenha a confiança e a pessoalidade como elemento preponderante da manutenção da união existente entre os sócios. Frisa-se que o próprio estatuto da sociedade poderia prever esta condição de pessoalidade como fundamento para manutenção da sociedade, contribuindo assim para a demonstração do caráter contratual desta.

\section{AÇÃO DE DISSOLUÇÃO PARCIAL DE SOCIEDADE}

\subsection{Princípio da preservação da empresa}

O princípio da preservação da empresa, demarcado de forma implícita no art. 170 da

$\mathrm{CR} / 88$, que estabelece uma ordem econômica fundada na livre iniciativa e na valorização do 
trabalho humano, foi expressamente consagrado no ordenamento pátrio pelo art. 47 da Lei 11.101/05. Com relação a este princípio, leciona Fabio Ulhoa Coelho (2012, p. 80):

O princípio da preservação da empresa reconhece que, em torno do funcionamento regular e desenvolvimento de cada empresa, não gravitam apenas os interesses individuais dos empresários e empreendedores, mas também os metaindividuais de trabalhadores, consumidores e outras pessoas; são estes últimos interesses que devem ser considerados e protegidos, na aplicação de qualquer norma de direito comercial.

O princípio em comento segrega, portanto, os interesses dos sócios dos interesses sociais, seja de trabalhadores, credores, fisco, ou demais afetados pela atividade empresarial. Nessa esteira, nota-se que há uma sobreposição da função social da empresa sobre a individualidade do sócio ou da sociedade empresária em si. Isso, pois, o interesse na manutenção da atividade empresarial parte não somente dos sócios, mas também de todos os indivíduos que se beneficiam desta, inclusive o próprio Estado.

Assim, o princípio da preservação da empresa existe com o fito de assegurar a manutenção das atividades empresárias, garantindo o alcance da sua finalidade social e contribuindo, deste modo, para uma economia mais saudável, com maior arrecadação tributária, garantia de empregos e circulação de bens e serviços.

\subsection{Dissolução parcial de sociedades anônimas}

Em observância ao princípio da preservação da empresa, a dissolução parcial de sociedades surgiu como alternativa à dissolução total, com o objetivo de evitar a extinção absoluta da sociedade empresária e garantir a sua continuidade, mantendo os empregos, recolhimentos tributários, a circulação de capital, dentre outros.

Anteriormente ao advento do Novo Código de Processo Civil, que introduziu no ordenamento jurídico pátrio previsões expressas acerca da ação de dissolução parcial de sociedades, o instituto era aplicado na prática com respaldo em entendimentos doutrinários e jurisprudenciais. Tais entendimentos foram construídos a partir da interpretação do art. 1.218, inciso VII, do Código de Processo Civil de 1973, conjugado com os art. 655 e seguintes do Código de Processo Civil de 1939.

Originalmente, a dissolução parcial constituiu-se voltada para as sociedades contratuais e personalistas, e não às sociedades institucionais ou de capital, conforme bem explica Celso Barbi Filho (2004, p. 59): 
Primeiramente, os acionistas não possuem vínculo contratual entre si. Adquirem ou transferem suas participações no capital - as ações - sem reflexos para a companhia, sempre regida pelos estatutos sociais promulgados no ato constitutivo da sociedade. Por essa razão, inexiste liame contratual a ser parcialmente dissolvido entre a sociedade e um ou alguns de seus acionistas. [...] Por outro lado, nas sociedades institucionais e capitalistas, sempre houve mecanismos específicos para a livre entrada e saída dos sócios, indispensáveis aos próprios fins do modelo corporativo de harmonização entre acionistas investidores e gestores. Assim sendo, institutos como a venda de ações em bolsa de valores, o direito de recesso, o resgate e a amortização de ações fizeram das sociedades institucionais e de capitais entidades nas quais não havia sentido a idéia de dissolução parcial. Ademais, sendo a sociedade predominantemente de capitais, na qual a identidade do sócio não é relevante, o eventual rompimento da affectio societatis - que muitos entendem inexistente nesse modelo societário - não seria justificativa para autorizar a saída do sócio insatisfeito, que ali deveria permanecer até que encontrasse um adquirente para sua participação.

Sob tais fundamentos, o entendimento adotado inicialmente pelo Superior Tribunal de Justiça foi pela impossibilidade de dissolução parcial da sociedade anônima, conforme se extrai da ementa de julgamento do Recurso Especial n. 419.174/SP, de relatoria do Ministro Carlos Alberto Menezes Direito, publicado em 28 de outubro de 2002:

SOCIEDADE ANÔNIMA. DISSOLUÇÃO PARCIAL. PRECEDENTES DA CORTE. 1. É incompatível com a natureza e o regime jurídico das sociedades anônimas o pedido de dissolução parcial, feito por acionistas minoritários, porque reguladas em lei especial que não contempla tal possibilidade. 2. Recurso especial conhecido e provido. (BRASIL, 2002)

Ocorre que, conforme demonstrado em tópico próprio, existem, atualmente, posições consistentes tanto na doutrina, quanto na jurisprudência, que apontam para a possibilidade de as sociedades anônimas serem enquadradas como sociedades contratuais ou de pessoas.

Seguindo esta linha interpretativa e com observância ao princípio da preservação da empresa, mas antes da entrada em vigor do Novo Código de Processo Civil, o Superior Tribunal de Justiça, ao julgar o Recurso Especial n. 1303284/PR, de relatoria da Ministra Nancy Andrighi, publicado em 13 de abril de 2013, consolidou entendimento no sentido de que a dissolução parcial de sociedade anônima é admitida, quando tratar-se de sociedade de cunho familiar:

EMPRESARIAL. SOCIEDADE ANÔNIMA FECHADA. CUNHO FAMILIAR. DISSOLUÇÃO. FUNDAMENTO NA QUEBRA DA AFFECTIO SOCIETATIS. POSSIBILIDADE. DEVIDO PROCESSO LEGAL. NECESSIDADE DE OPORTUNIZAR A PARTICIPAÇÃO DE TODOS OS SÓCIOS. CITAÇÃO INEXISTENTE. NULIDADE DA SENTENÇA RECONHECIDA. 1. Admite-se dissolução de sociedade anônima fechada de cunho familiar quando houver a quebra da affectio societatis. 2. A dissolução parcial deve prevalecer, sempre que possível, 
frente à pretensão de dissolução total, em homenagem à adoção do princípio da preservação da empresa, corolário do postulado de sua função social. 3 . Para formação do livre convencimento motivado acerca da inviabilidade de manutenção da empresa dissolvenda, em decorrência de quebra da liame subjetivo dos sócios, é imprescindível a citação de cada um dos acionistas, em observância ao devido processo legal substancial. 4. Recurso especial não provido. (BRASIL, 2013)

Nessa mesmo sentido manifestou-se o Ministro Luis Felipe Salmoão, do Superior Tribunal de Justiça, no voto do Recurso Especial n. 917.531/RS, publicado em 01 de fevereiro de 2012:

É bem de ver que o art. 206, II, 'b', da Lei das S/A contempla hipótese de dissolução total da companhia por decisão judicial, quando provado que ela não pode preencher o seu fim, o que sói ocorrer quando há desinteligência entre os acionistas, uma vez que dificilmente pode prosperar uma sociedade em que a confiança, a harmonia, a fidelidade e o respeito mútuo entre os seus sócios tenham sido rompidos.

Todavia, a regra da dissolução total em nada beneficiaria os valores sociais envolvidos no que diz respeito à preservação de empregos, arrecadação de tributos e desenvolvimento econômico do país, razão pela qual o rigorismo legislativo deve ceder lugar ao princípio da preservação da empresa, implicando a sua continuidade em relação aos sócios remanescentes.

$\mathrm{O}$ instituto da dissolução parcial erigiu-se, em sua gênese, voltado às sociedades contratuais e personalistas, como alternativa à dissolução total e, portanto, como medida mais consentânea ao princípio da preservação da sociedade e sua função social, contudo deve-se reiterar que a complexa realidade das relações negociais hodiernas potencializa a extensão daquele instituto às sociedades 'circunstancialmente' anônimas. (BRASIL, 2012)

O Superior Tribunal de Justiça vem, portanto, já há algum tempo, firmando sólido entendimento no sentido de que a possiblidade jurídica do pedido de dissolução parcial de sociedade anônima deverá ser examinada sob o prisma da essência de sua constituição, a fim de se verificar se se trata de uma sociedade de capital, com características institucionais, ou de uma sociedade de pessoas, eminentemente contratual.

O Código de Processo Civil em vigor consolidou a possibilidade de a sociedade anônima ser objeto de ação de dissolução parcial. Seguindo o caminho do art. 206, II, "b", da Lei 6.404/76, o mencionado diploma processual, em seu art. 599, §2 ${ }^{\circ}$, determinou expressamente que a ação de dissolução parcial de sociedade pode ter por objeto a sociedade anônima de capital fechado, desde que demonstrado por acionistas, que representem no mínimo 5\% (cinco por cento) do capital social, que aquela não pode preencher o seu fim.

\section{EXCLUSÃO DE SÓCIOS NAS SOCIEDADES ANÔNIMAS}




\subsection{Impossibilidade de preenchimento da finalidade social e exclusão de sócios}

Conforme lecionam Nelson Nery Junior e Rosa Maria de Andrade Nery (2016, p. 1526 - grifo do autor), a redação dada ao art. 599, $\$ 2^{\circ}$, do Novo Código de Processo Civil é obscura, mas a interpretação mais correta seria no sentido de que a impossibilidade de preenchimento do fim social se dá exatamente em função da não dissolução parcial:

11. Dissolução parcial e 'não preenchimento do fim'. O CPC 599 § $2 .^{\circ}$ é de redação obscura. Em se tratando de uma ação de dissolução parcial, é possível que a propositura dessa mesma ação seja motivada pelo não preenchimento do objetivo da sociedade? Isso dá a entender que a sociedade quer se dissolver completamente. A interpretação mais correta, no caso, seria no sentido de que a impossibilidade de preenchimento do fim social se dá em função da não dissolução parcial.

Diante do requisito imposto pelo dispositivo em comento, de se comprovar a impossibilidade de alcance da finalidade social para fins de dissolução parcial da sociedade, mister se faz uma breve análise acerca das razões que poderiam ensejar a exclusão de acionistas, com base em tal dispositivo.

No intuito de evitar conflitos entre os sócios, causados por abuso de poder ou outras medidas destituídas de espírito cooperativo, a Lei 6.404/76 instituiu alguns mecanismos específicos, pautados nos deveres de cooperação, lealdade, informação, dentre outros. Assim, em muitos casos, o sócio que se pretende excluir pode, alternativamente, ter sua conduta readequada pela utilização de tais mecanismos, sem que isso importe em sua exclusão, que poderia comprometer os investimentos da companhia. A respeito do tema, confira-se as lições de Mário Engler Pinto Junior (1983, p. 88):

É forçoso se reconhecer que a conduta antijurídica do acionista, no mais das vezes, pode ser satisfatoriamente corrigida pelo sucedâneo reparatório, ou por outros meios alternativos, v.g., a anulação do ato abusivo, ou a convalidação de ato, embora sem a sua colaboração ativa considerada indispensável. Em outras palavras, as violações ao dever de cooperação, omissivo ou comissivo, imposto ao sócio da sociedade anônima, normalmente não provoca um impedimento juridicamente insuperável à realização do objeto social. Dessa forma, a exclusão torna-se irrelevante, podendo até redundar em prejuízo à própria companhia, pelo desfalque patrimonial decorrente do reembolso de capital devido ao acionista excluído.

É facilmente reconhecível, entretanto, a possibilidade de haver situações em que a manutenção de determinado sócio na companhia coloque em risco o bom andamento de suas atividades e a sua própria subsistência, conforme leciona, em ato contínuo, o supracitado doutrinador (PINTO JUNIOR, p. 88): 
Todavia, é perfeitamente possível se vislumbrar determinadas situações, onde a permanência do acionista na companhia venha a pôr em risco a sua sobrevivência como um todo, bem como a continuação da atividade empresarial. Esta ameaça pode ter origem num comportamento ilícito, cuja reparação não possa ser alcançada por nenhum dos mecanismos protetivos previstos na lei societária, ainda, ser resultado de fatores alheios à própria vontade do acionista.

Ainda, os mecanismos previstos pela Lei das Sociedades Anônimas são, muitas vezes, insuficientes para resguardar de forma efetiva os interesses da sociedade em face de acionistas que estejam eventualmente colocando em risco as atividades sociais. Esta realidade pode ser verificada a partir das lições de Eduardo Goulart Pimenta (2004, p. 135):

É certo que a atual lei do anonimato prevê sanções especiais para a figura do voto abusivo [...]. A verdade é que tais sanções legalmente previstas se mostram insuficientes para salvaguardar a companhia e a empresa dos acionistas que reiteradamente agirem contra os interesses daquela. Por um lado, parece-nos claro que a anulação da deliberação assemblear baseada em voto abusivo é medida que, se frequente, atravanca de modo irremediável o andamento das atividades sociais. Já a reparação mediante perdas e danos é a um só tempo demorada e complexa, faltando-lhe a devida agilidade que permita sua frequente utilização. A suspensão dos direitos do acionista, por fim, também não se mostrará eficaz quando o membro em questão permanecer violando seus deveres de colaboração para com a companhia.

Ademais, a instauração de um eventual conflito entre sócios pode resultar em verdadeira obstrução ao desenvolvimento das atividades sociais, pois, neste caso, podem ocorrer votos abusivos, que contrariam os interesses da sociedade. O supracitado doutrinador (PIMENTA, 2004, p. 135) defende, a título elucidativo, que a prática de voto abusivo poderia, inclusive, dar ensejo à exclusão de acionista:

Modalidade de voto abusivo particularmente interessante para o presente estudo se encontra na referência a abuso de voto pela minoria, positivada no $\S 3^{\circ}$ do art. 115 da Lei 6.404/76. Tal figura não é estranha ao mundo fático das companhias, onde muitas vezes as minorias obstruem o andamento dos trabalhos, até mesmo impedindo que se forme a maioria para a efetivação da deliberação. Nesse sentido, pode-se questionar se a recusa sistemática em votar determinada deliberação, impedindo a sua aprovação, que é reputada essencial à companhia, constituiria motivo para a exclusão do acionista.

Em tópico anterior, foi colacionada a ementa de julgamento do Recurso Especial $\mathrm{n}$. 1303284/PR, de relatoria da Ministra Nancy Andrighi, em que foi reconhecida a possibilidade de se dissolver parcialmente uma sociedade anônima de cunho familiar por quebra da affectio societatis (intuitu personae). No caso específico da exclusão de sócio, tal argumento, por si só, não parece ser causa hábil a fundamentar o pedido, conforme lecionam Erasmo Valladão Azevedo e Novaes França e Marcelo Vieira von Adamek (2008, p. 125): 
Na realidade, a quebra de affectio societatis jamais pode ser considerada causa de exclusão. Pelo contrário, a quebra de affectio societatis é, quando muito, consequência de determinado evento, e tal evento, sim, desde que configure quebra grave dos deveres sociais imputável ao excluendo, poderá, como ultima ratio, fundamentar o pedido de exclusão de sócio. Em todo caso, será indispensável demonstrar o motivo desta quebra da affectio societatis, e não apenas alegar a consequência, sem demonstrar sua origem e o inadimplemento de dever de sócio que aí possa estar. A quebra de affectio societatis, insista-se, não é causa de exclusão de sócio; o que pode eventualmente justificar a exclusão de sócios é a violação dos deveres de lealdade e de colaboração [...].

Seguindo o mesmo caminho, o Superior Tribunal de Justiça, no julgamento do Recurso Especial 1129222/PR, publicado em 01 de agosto de 2011, de relatoria da própria Ministra Nancy Andrighi, firmou o entendimento de que não cabe a exclusão de sócios por mera alegação de quebra do affectio societatis, devendo ser demonstrados os motivos que ocasionaram essa quebra:

CIVIL E COMERCIAL. RECURSO ESPECIAL. DISSOLUÇÃO PARCIAL DE SOCIEDADE. EXCLUSÃO DE SÓCIO. QUEBRA DA AFFECTIO SOCIETATIS. INSUFICIÊNCIA. 1. A ausência de decisão sobre o dispositivo legal supostamente violado, não obstante a interposição de embargos de declaração, impede o conhecimento do recurso especial. Incidência da Súmula 211/STJ. 2. O reexame de fatos e provas em recurso especial é inadmissível. 3. Deficiência de fundamentação do recurso. Incidência da Súmula 284/STF. 4. Inexiste ofensa ao art. 535 do CPC, quando o tribunal de origem pronuncia-se de forma clara e precisa sobre a questão posta nos autos. 5. Para exclusão judicial de sócio, não basta a alegação de quebra da affectio societatis, mas a demonstração de justa causa, ou seja, dos motivos que ocasionaram essa quebra. 6. Recurso especial a que se nega provimento. (BRASIL, 2011)

Em determinados casos, portanto, as condutas reprováveis de acionistas podem prejudicar o regular exercício das atividades empresariais, comprometendo a finalidade social e ensejando a possibilidade de exclusão da sociedade anônima, conforme se infere do trecho da ementa de julgamento abaixo, referente ao já mencionado Recurso Especial n. 917.531/RS:

DIREITO SOCIETÁRIO E EMPRESARIAL. SOCIEDADE ANÔNIMA DE CAPITAL FECHADO EM QUE PREPONDERA A AFFECTIO SOCIETATIS. DISSOLUÇÃO PARCIAL. EXCLUSÃO DE ACIONISTAS. CONFIGURAÇÃO DE JUSTA CAUSA. POSSIBILIDADE. APLICAÇÃO DO DIREITO À ESPÉCIE. ART. 257 DO RISTJ E SÚMULA 456 DO STF. [...] 3. Em outras palavras, a exclusão é medida extrema que visa à eficiência da atividade empresarial, para o que se torna necessário expurgar o sócio que gera prejuízo ou a possibilidade de prejuízo grave ao exercício da empresa, sendo imprescindível a comprovação do justo motivo. [...]. (BRASIL, 2012)

Diante das breves considerações realizadas, pode-se concluir que, em determinados casos, os atos que culminaram na quebra da relação de confiança entre acionistas podem 
importar em verdadeiro óbice ao alcance da finalidade social, podendo tal situação, nesse sentido, ensejar o ajuizamento de ação de dissolução parcial da sociedade, para exclusão do sócio causador do conflito, com base no art. 599, $\$ 2^{\circ}$ do Novo Código de Processo Civil.

\subsection{Fundamentos para exclusão de sócios: aplicação subsidiária do Código Civil às sociedades anônimas}

Conforme já apontado anteriormente, no que tange especificamente à exclusão de sócios, a Lei 6.404/76 prevê uma única possibilidade: exclusão do sócio remisso (art. 106 e 107). Não obstante, a mencionada Lei não veda a possibilidade de exclusão de acionistas.

O Código Civil, por seu turno, ao instituir o regramento das sociedades limitadas, estabelece expressamente as situações em que os sócios podem ser excluídos judicialmente: (i) descumprimento da obrigação de integralizar o capital social (sócio remisso - art. 1.004, Parágrafo único); (ii) falta grave no cumprimento de obrigações ou incapacidade superveniente (art. 1.030); ou (iii) decretação de falência ou liquidação de quota por credor (art. 1.030, Parágrafo único, c/c art. 1.026, Parágrafo único).

O direito de exclusão de sócio neste âmbito, portanto, existe, em sua essência, para que o interessado possa promover a desvinculação jurídica daquele que esteja prejudicando, ou possa prejudicar, as atividades sociais. Infere-se, nesse sentido, que no âmbito do Código Civil, a exclusão de sócios tem um alcance mais extenso do que aquele amparado pela Lei $6.404 / 76$.

O Código Civil, em seu art. 1.089, estabelece que a sociedade anônima será regida por lei especial, aplicando-se, nos casos omissos, as disposições nele previstas. Com efeito, defende-se que as causas previstas no Código Civil para exclusão de sócios podem ser aplicadas no âmbito das sociedades anônimas, notadamente daquelas de capital fechado e marcadas pela pessoalidade e confiança entre os acionistas. Fica ressalvada, neste caso, a inexistência de previsão estatutária que: (i) proíba a aplicação subsidiária do Código Civil; ou (ii) vede a exclusão de sócios.

A aplicação subsidiária do Código Civil defendida acima é corroborada pelo Ministro Luis Felipe Salomão, do Superior Tribunal de Justiça, que, em voto para julgamento do já citado Recurso Especial n. 917.531/RS, afirmou:

Nessa esteira de intelecção, caracterizada a sociedade em tela como fechada e personalista, o que tem o condão de propiciar a sua dissolução parcial - 
fenômeno até recentemente vinculado às sociedades de pessoas -, é de se entender pela possibilidade de aplicação das regras atinentes à exclusão de sócios das sociedades regidas pelo Código Civil, máxime diante da previsão contida no art. 1.089 do CC: 'A sociedade anônima rege-se por lei especial, aplicando-se-lhe, nos casos omissos, as disposições deste Código.' Ademais, a Lei 6.404/76 não veda que o estatuto social prescreva hipóteses e procedimentos de exclusão de sócio, tendo em vista o caráter regulamentador que assume tal ato constitutivo das sociedades anônimas. (BRASIL, 2012)

Nesse sentido, mostra-se coerente a possibilidade de exclusão de sócios de sociedades anônimas com caráter contratual ou pessoal, a partir da aplicação das hipóteses previstas no Código Civil, e não apenas nos casos em que a parte demonstre, nos termos do art. 599, §2 , do Novo Código de Processo Civil, e art. 206, II, “b”, da Lei 6.404/76, a impossibilidade de preenchimento da finalidade social.

O inciso I do art. 599 do Código de Processo Civil em vigor determina que a ação de dissolução parcial de sociedade, contratual ou simples, pode ter por objeto a resolução da sociedade em relação ao sócio: (i) falecido; (ii) excluído; ou que exerceu o direito de (iii) retirada; ou (iv) recesso. A resolução de sociedade simples ou contratual em relação a um sócio, para fins de dissolução parcial, abrange, portanto, algumas espécies distintas, sendo que a exclusão de sócios é uma delas.

À primeira vista, este dispositivo não poderia ser invocado no âmbito das sociedades anônimas, tendo em vista sua restrição às sociedades simples ou contratuais. Entretanto, foi amplamente demonstrado em tópico próprio que tanto a doutrina, quanto a jurisprudência do Superior Tribunal de Justiça, tem acatado a possibilidade de uma sociedade anônima se enquadrar como sociedade contratual ou de pessoas.

Em se tratando de sociedade anônima fechada, de pequeno ou médio porte, que não realize captações no mercado financeiro, e, ainda, que tenha a confiança e a pessoalidade como elemento preponderante da união entre os sócios, resta evidenciado o caráter contratual da sociedade, e afastado o caráter institucional, típico das grandes empresas capitalistas.

Ainda, a aplicação subsidiária do Código Civil, especialmente às sociedades anônimas delineadas acima, reforça o entendimento de que estas podem se socorrer ao inciso I do art. 599 do Novo Código de Processo Civil para excluir acionistas, eis que este seria um caminho processual viável para a tomada de tal medida.

Nesse sentido, defende-se uma superação à limitação imposta pelo art. 599, §2 , do Código de Processo Civil vigente às sociedades anônimas, com as características citadas, que 
poderiam se socorrer no Código Civil para eventualmente excluir algum sócio que esteja causando prejuízos à sociedade, ou cometendo atos graves, passíveis de comprometer o bom desenvolvimento das atividades empresariais.

Com efeito, além de possuir meios para excluir acionistas que comprometam o alcance da finalidade social, a sociedade anônima familiar poderia excluir sócios que cometessem falta grave no cumprimento de obrigações, que incorressem em incapacidade superveniente, ou em caso de decretação de falência ou liquidação de participação societária por credor.

\section{CONCLUSÃO}

Conforme amplamente discorrido no presente trabalho, há, no Brasil dos dias de hoje, um número imenso de sociedades anônimas que, embora constituídas sob referido tipo, marcado pela mera contribuição material, tratam-se de verdadeiras sociedades de pessoas, onde o affectio societatis (intuitu personae) e a vontade dos sócios é o que mantém a união ativa e garante o efetivo exercício das atividades sociais.

Uma vez que, nestas sociedades, a confiança é quebrada, os sócios acabam por adotar condutas que vão de encontro com os interesses sociais, comprometendo, muitas vezes, a própria existência da sociedade e da atividade empresária. Diante deste contexto, o Superior Tribunal de Justiça, acertadamente, vem decidindo pela possibilidade de se excluir acionistas de sociedades anônimas caracterizadas pela pessoalidade e de cunho familiar, por meio da dissolução parcial desta.

Com a reforma de lei processual civil, esta possibilidade se consolidou, com a introdução de normas que autorizam expressamente a dissolução parcial de sociedades anônimas. Não obstante o advento do mencionado diploma processual ter representado verdadeira evolução quanto à matéria, a possibilidade efetiva de exclusão de sócios das sociedades anônimas ainda gera alguma dúvida, notadamente no que tange às hipóteses em que tal medida pode ser adotada.

Nesse sentido, o presente estudo buscou demonstrar a possibilidade de exclusão de sócios da sociedade anônima, tanto em decorrência do comprometimento do alcance da finalidade social (NCPC, art. 599, $\S 2^{\circ}$ ), quanto por aplicação das normas concernentes às sociedades simples e limitadas, previstas no Código Civil (art. 1.004 e art. 1.030). No que 
tange à aplicação das normas previstas no Código Civil, defendeu-se, ainda, a possibilidade de a sociedade anônima se socorrer ao art. 599, I, do Novo Código de Processo Civil, para pleitear a exclusão de sócio, por meio de ação de dissolução parcial de sociedade.

Por meio da interpretação defendida, busca-se proporcionar maior eficiência às atividades empresariais, especialmente considerando que, muitas vezes, os mecanismos legais para mitigação de atos abusivos por parte dos sócios podem não alcançar a finalidade esperada.

\section{REFERÊNCIAS}

BARBI FILHO, Celso. Dissolução Parcial de Sociedades Limitadas. Belo Horizonte: Mandamentos, 2004.

BRASIL. Superior Tribunal de Justiça. Recurso Especial n. 917.531/RS, Quarta Turma, Rel. Ministro Luis Felipe Salomão, Recorrentes: Richard David Valansi e outro, Recorridos: Patrick Maurice Maxime Valansi e outros, 01/02/2012. Disponível em: $<$ https://ww2.stj.jus.br/

processo/revista/documento/mediado/?componente=ATC\&sequencial=18563300\&num_regis tro $=200700073925 \&$ data $=20120201 \&$ tipo $=91 \&$ formato $=P D F>$. Acesso em 10 de maio de 2017.

Superior Tribunal de Justiça. Embargos de Divergência no Recurso Especial n. 111.294/PR, Segunda Seção, Rel. Ministro Castro Filho, Recorrente: Cocelpa Companhia de Celulose e Papel do Paraná e outros, Recorrido: Aurélio Fontana de Pauli - Espólio e outro, 10/09/2007. Disponível em: <https://ww2.stj.jus.br/processo/revista/documento/mediado/? componente $=$ ATC $\&$ sequencial $=2505364 \&$ num_registro $=200201005006 \&$ data $=20070910 \& \mathrm{ti}$ po $=5 \&$ formato $=\mathrm{PDF}>$. Acesso em 10 de maio de 2017.

Superior Tribunal de Justiça. Recurso Especial n. 419.174/SP, Terceira Turma, Rel. Ministro Carlos Alberto Menezes Direito, Recorrente: Espólio de Ludwig Kirchner e outros, Recorrido: Luiz Kirchner S/A Indústria de Borracha, 28/10/2002. Disponível em: $<$ https://ww2.stj.jus.br/processo/revista/documento/mediado/?componente=ATC\&sequencial $=632928 \&$ num_registro $=200200284189 \&$ data $=20030224 \&$ tipo $=5 \&$ formato $=P D F>$. Acesso em 10 de maio de 2017.

Superior Tribunal de Justiça. AgRg no Ag 34.120/SP, Terceira Turma, Rel. Ministro Dias Trindade, Recorrente: Giusti e Companhia Ltda., Recorrido: Permetal S/A Metais Perfurados, 14/06/1993. Disponível em: <https://ww2.stj.jus.br/processo/ita/documento/ mediado/?num_registro=199300046659\&dt_publicacao=14-06-1993\&cod_tipo_documento= 1>. Acesso em 10 de maio de 2017.

Superior Tribunal de Justiça. Recurso Especial n. 1303284/PR, Terceira Turma, Rel. Ministra Nancy Andrighi, Recorrente: Aurélio Fontana de Pauli - Espólio, Recorrido: 
Antônio de Pauli S/A, 13/05/2013. Disponível em: <https://ww2.stj.jus.br/processo/revista/ documento/mediado/?componente $=$ ATC \&sequencial=27102415\&num_registro $=2012000669$ $15 \&$ data $=20130513 \&$ tipo=5\&formato=PDF $>$. Acesso em 10 de maio de 2017.

Superior Tribunal de Justiça. Recurso Especial n. 1.129.222/PR, Terceira Turma, Rel. Ministra Nancy Andrighi, Recorrente: Seme Raad e outro, Recorrido: Faissal Assad Raad e outro, 01/08/2011. Disponível em: https://ww2.stj.jus.br/processo/revista/documento/ mediado/?componente $=$ ATC $\&$ sequencial $=16340522 \&$ num_registro $=200900512578 \&$ data $=2$ 0110801\&tipo=5\&formato=PDF. Acesso em 10 de maio de 2017.

CICU, Antonio. El derecho de Familia. (trad. Santiago Sentis Melendo). Buenos Aires: Ediar S.A. Editores, 1947.

COELHO, Fábio Ulhoa. Curso de direito comercial, vol. 1 e vol. 2: direito de empresa, $16^{\mathrm{a}}$ ed. São Paulo: Saraiva, 2012.

HARIOU, Maurice. La teoria de la institución y de la fundación. (trad. Arturo Enrique Sampay). Buenos Aires: Abeledo-Perrot, 1968.

MARTINS, Fran. Comentários à Lei das Sociedades Anônimas. Rio de Janeiro: Editora Forense, 2011.

NERY JUNIOR, Nelson; NERY, Rosa Maria de Andrade. Código de processo civil comentado. 16 $6^{\text {a }}$. São Paulo: Editora Revista dos Tribunais, 2016.

NOVAES FRANÇA, Erasmo Valladão Azevedo e VON ADAMEK, Marcelo Vieira. Affectio Societatis: um conceito jurídico superado no moderno direito societário pelo conceito de fim social. Revista de Direito Mercantil. São Paulo: Malheiros Editores, ns. 149/150, 2008.

PIMENTA, Eduardo Goulart. Exclusão e retirada de sócios. Belo Horizonte: Decálogo Livraria e Editora, 2004.

PINTO JUNIOR, Mário Engler. Exclusão de acionista. Revista de Direito Mercantil. n. 54, São Paulo: Revista dos Tribunais, 1983.

REQUIÃO, Rubens. Curso de Direito Comercial, $1^{\circ}$ vol. Saraiva. 1993.

REQUIÃO, Rubens. Curso de Direito Comercial, $2^{\circ}$ volume, $27^{a}$ ed. São Paulo: Saraiva, 2010.

RIZZARDO, Arnaldo. Direito de empresa: Lei ${ }^{\circ}$ 10.406, de 10.01.2002. Rio de Janeiro: Forense, 2007.

TOMAZETTE, Marlon. Curso de direito empresarial: teoria geral e direito societário, vol. I. $5^{\text {a }}$ ed. São Paulo: Atlas, 2013. 